\title{
A História da Expansão da Inclusấo Escolar e as Demandas para o ENSINO COMUM VeICUladas POR UM JORNAL ${ }^{1}$ \\ The History of Expansion of SCHOOL InCLUSion and the Demands of REGULAR EDUCATION DISSEMINATED BY A NEWSPAPER
}

\author{
Keisyani da Silva SANTOS ${ }^{2}$ \\ Enicéia Gonçalves MENDES ${ }^{3}$
}

\begin{abstract}
RESUMO: Na transição do século XX para o XXI, com o advento do movimento internacional para a Educação Inclusiva, a Educação Especial brasileira começou a traçar novos rumos para sua história, e transformaçóes significativas na condução das políticas educacionais começaram a ocorrer em todo o país. Considerando que a história da Educaçâo Especial brasileira tem sido descrita predominantemente com base em textos oficiais, o presente estudo teve como objetivo recontar e analisar as histórias sobre a repercussão da expansão da inclusão escolar e as demandas para o ensino comum em um jornal de grande circulação no país. O corpus documental foi constituído por 295 textos publicados no jornal O Estado de S. Paulo no período de 1997 a 2004 , que dispuseram ao menos de um descritor previamente estabelecido. Ao se resgatar algumas histórias contadas pelo jornal, pôde-se identificar o aumento no número de matrículas do público-alvo da Educação Especial no ensino regular, com destaques para a exposição de experiências bem-sucedidas de inclusão escolar nas escolas privadas, ao passo que, no caso das escolas públicas, foram retratados problemas e desafios. Assim, a ideologia decorrente do confronto dessas histórias é discutida.
\end{abstract}

PALAVRAS-CHAVE: Educação Especial. História. Inclusão escolar. Jornal.

\begin{abstract}
In the transition from the 20th to the 21st century, with the coming of the international movement to Inclusive Education, the Brazilian Special Education started to draw new directions to its history, and significant transformations in the conduct of education policies began to occur throughout the country. Considering that the history of Brazilian Special Education has been described predominantly based on official texts, this study had the objective of retelling and analyzing the stories about the repercussion of the expansion of school inclusion and the demands for the regular teaching in a newspaper of great circulation in the country. The documentary corpus consisted of 295 texts published in the newspaper O Estado de S. Paulo from 1997 to 2004, which were disposed of at least one describer, previously established. By bringing back some stories told by the newspaper, it was possible to identify an increase in the number of enrollments of the target population of Special Education in regular education, with an emphasis on the exposition of successful experiences of school inclusion in private schools, whereas, in the case of public schools, problems and challenges were portrayed. Thus, the ideology arising from the confrontation between these stories is discussed.
\end{abstract}

KEYWORDS: Special Education. History. School Inclusion. Newspaper.

\section{HistóRIA DA EDUCAÇÁo ESPECIAL: UMA ÁREA DE PESQUISA EM CRESCIMENTO}

A partir do pressuposto de que não há uma história única e verdadeira, consequentemente assume-se também a multiplicidade das formas de se produzir o conhecimento histórico. Entretanto, durante um longo tempo, a história da Educação Especial foi pensada e produzida sob a perspectiva política e normativa, na qual os documentos oficiais e legais foram as principais fontes históricas utilizadas pelos pesquisadores. Tais características não são exclusivas desse campo, pois, por um período, imperava a concepção de que a história genuína e científica deveria ser produzida a partir de registros escritos, sobretudo os oficiais, pois estes continham valor

\footnotetext{
${ }^{1}$ http://dx.doi.org/10.1590/S1413-65382418000400009

${ }^{2}$ Mestre em Educação Especial pela Universidade Federal de São Carlos (UFSCar), São Carlos-SP, Brasil. keisyani@gmail.com.

${ }^{3}$ Doutora em Psicologia e Professora do Departamento de Psicologia (DPsi) pela Universidade Federal de São Carlos (UFSCar), São Carlos- SP, Brasil. eniceia.mendes@gmail.com.
} 
de prova e verdade histórica (Meirelles, 2002). Contudo, a noção de documento, como fonte histórica válida, foi reformulada, originando a chamada revoluçáo documental. Em meados do século XX, o entendimento sobre o que vem a ser um documento foi ampliado, aceitando-se textos escritos e, também, "[...] documentos de natureza iconográfica e cinematográfica, ou de qualquer outro tipo de testemunho registrado, objetos do cotidiano, elementos folclóricos etc." (Cellard, 2008, p. 297).

Vale destacar as contribuiçóes ímpares da Escola dos Annales para a revolução documental e dos modos de se pensar e fazer história. Assim, a disciplina História deixou de ser entendida como a ciência que investiga e reconstitui o passado, e passou a ser compreendida como a ciência que estuda o homem em determinado tempo e espaço social, ressaltando a importância da compreensão dos processos históricos, de questioná-los e analisá-los de forma crítica e contextualizada. Nas palavras de Le Goff (2003, p. 15), simplesmente a "ciência da mutação e da explicação dessa mudança”.

A História da Educação Especial brasileira, por outro lado, tem sido um tema pouco abordado nas pesquisas, principalmente de estudos usando fontes náo tradicionais. Em revisão atualizada dos artigos disponibilizados no Portal de Periódicos da Capes, identificaram-se apenas 22 artigos relacionados a esse tema, e, embora se observe ao longo da última década um aumento significativo da produção científica sobre o assunto - considerando-se uma produção de quatro artigos de 1993 a 2009 contra 18 textos publicados entre 2010 a 2017 -, em números absolutos, o crescimento identificado é ainda tímido. A Revista Brasileira de Educação Especial (RBEE) foi a que mais publicou sobre o tema, com 13 artigos publicados nos últimos 15 anos. Tal dado mostra uma mudança importante para a área, considerando que, até o ano de 2002, apenas um artigo sobre história da Educação Especial havia sido publicado na revista, configurando um dos temas de mais baixa produção veiculado pela RBEE (Manzini, 2003).

Quanto aos artigos publicados nos últimos 25 anos sobre a História da Educação Especial, percebe-se que há um movimento de renovação das fontes do saber histórico. A principal fonte foi a própria produção acadêmica $(n=8)$; a segunda, os textos oficiais $(n=6)$, com destaque para a utilização dos textos legislativos e normativos de âmbito nacional para a Educação Especial, sobre a política atual sob a perspectiva da Educação Inclusiva. Ainda que apresentando frequência baixa $(n=7)$, considera-se relevante destacar a utilização dos relatos orais de pessoas com deficiência $(n=5)$ e de professores $(n=2)$ como fonte do saber histórico. Com esses estudos, pode-se observar, no campo da Educação Especial, o acompanhamento do início de uma tendência da diversificação das fontes, bem como a valorização de personagens até então ignorados pelos estudos históricos.

Especificamente no campo da História da Educação, novas fontes documentais passaram a ser consideradas válidas e valiosas, como, por exemplo, "as tradições orais, as publicaçóes periódicas, as biografias e as autobiografias, os relatos de vida escolar, a iconografia, os materiais didáticos, os cadernos escolares" (Nóvoa, 1997, p. 19), revelando novas histórias, a partir de diferentes perspectivas, olhares e fontes. Zanlorenzi (2010, p. 64) aponta a utilização do jornal, e da mídia impressa em geral, como fonte documental histórica promissora, pois permite "analisar o contexto educacional e as relaçóes envolvidas nesse processo". 
Ao problematizar o uso do jornal diário como fonte de dados para a pesquisa em História da Educação, Vieira (2007, p. 13) argumenta que o jornal é uma fonte documental preciosa, que permite conhecer, investigar e analisar "dos personagens ilustres aos anônimos, do plano público ao privado, do político ao econômico, do cotidiano ao evento, da segurança pública às esferas cultural e educacional". As fontes históricas oriundas da mídia têm sido cada vez mais utilizadas como fontes primárias, ou seja, fontes produzidas que possuem uma relação direta com as questóes de pesquisa (Toledo \& Gimenez, 2009). Assim, a produçáo científica tem se apropriado desse tipo de fonte, deixando de utilizá-la somente como fonte secundária, cuja relação é indireta com o tema a ser investigado.

Apesar das fontes documentais oriundas na mídia impressa serem consideradas relevantes e promissoras, no campo da Educação Especial, pouco se tem utilizado desta para a análise e construção de sua história. Em alguns casos, o material produzido pela mídia impressa tem sido explorado especificamente com o objetivo de identificar concepçóes e representaçóes acerca das pessoas com deficiência.

Ao analisar a atuação da mídia como veículo de comunicação e de representaçóes de discursos e ideologias, Pontes, Naujorks e Sherer (2001) concluíram que a mídia era uma forte catalisadora de estereótipos. No ano de 2003, a Agência de Notícias dos Direitos da Infância (ANDI), uma organização da sociedade civil, publicou o documento Midia e Deficiência, com os resultados obtidos na pesquisa que investigou o tema da deficiência nos jornais brasileiros, a qual concluiu que a sociedade náo havia se apropriado do discurso inclusionista, estando ainda muito pautada nos princípios de integração, considerado pelas autoras ultrapassado e obsoleto.

Vimieiro e Maia (2011), por outro lado, investigaram a cultura pública mediada sobre o tema da deficiência de 1960 a 2008 no Brasil e concluíram que havia um profundo processo de aprendizado social, na aceitação das pessoas com deficiência, principalmente no tocante à inclusão dessa população na sociedade.

Com o intuito de analisar historicamente a produção veiculada pela mídia impressa, especificamente em um jornal local, foi realizada uma série de pesquisas integradas que tiveram como objetivo central a reconstrução da História da Educação Especial do município de São Carlos, interior do estado de Sáo Paulo, em um período de 25 anos, especificamente, de 1981 a 2010 (Santos, 2013; Grillo-Stábille, 2013; Gouveia, 2013). As evidências baseadas na História da Educação Especial do município de São Carlos, contada pelo jornal local, mostraram que a filantropia e a Educação Especial continuavam imbricadas, em uma relação simbiótica, a despeito de todo o avanço do discurso sobre Educação Inclusiva.

Assim, como as pesquisas e a historiografia se fazem com base em problematizações oriundas e próprias de cada tempo, o presente estudo teve como objetivo recontar e analisar as histórias sobre a repercussão da expansão da inclusão escolar e as demandas para o ensino comum em um jornal de grande circulação no país, contrapondo matérias que abordaram escolas públicas versus escolas privadas. Fundamentalmente o que se buscou foi recontar essas histórias a partir da aprovação da Lei de Diretrizes e Bases (LDB) (Lei No 9.394, de 20 de dezembro de 1996) até se chegar ao período considerado o "boom da política de inclusão escolar" (Mendes, Santos, \& D’Affonseca, 2016) no ano de 2004, pois, em função da matrícula quase que compulsória dos alunos do público-alvo da Educação Especial, o Censo Escolar indicou que a 
proporção de alunos em escolas comuns ultrapassou a das instituiçôes especializadas. Com a finalidade de delimitar melhor o estudo, e de apresentar a importância do jornal como fonte para a construção de novas histórias, foi selecionado um jornal de grande circulação no país.

\section{SíNTESE Do PERCURSO METODOLÓGICO}

Com base nos postulados da Nova História, utilizou-se como fonte histórica o jornal $O$ Estado de S. Paulo (OESP), em suas duas ediçóes diárias: nacional e local. A busca pelos textos foi realizada no acervo digital do jornal, que disponibilizava online, mediante pagamento de assinatura, todas as suas ediçóes. Com a utilização de 42 descritores, termos referentes à Educação Especial, foi feita a identificação e a seleção dos textos jornalísticos a serem analisados, publicados no período de 1997 a 2004.

Inicialmente, 698 textos publicados no jornal foram identificados, mas, após uma primeira análise, verificou-se que 58\% (n=403) não tinha a Educação Especial como foco, apesar de conter no corpo do texto referências educacionais relacionadas ao tema. Desse universo, 77,5\% ( $\mathrm{n}=312)$ dos textos estavam relacionados à Associaçáo de Pais e Amigos dos Excepcionais (APAE) de São Paulo, sobretudo em notas de colunas sociais com ampla divulgação da realização de seus eventos beneficentes para a elite paulista. Os anos de maior frequência foram 2004 e 2002, com amostra correspondente a 14,9\% e 15,3\% ( $n=104$ e 107 textos), respectivamente. $\mathrm{O}$ ano de 1997 foi o de menor frequência de matérias, cuja amostra correspondeu a $6,3 \%$ textos $(n=44)$.

O processo de análise envolveu a categorização dos textos, de acordo com o conteúdo. Após esse procedimento, todos os textos, pertencentes à categoria inclusáo escolar - tema de maior frequência em todo o período -, seguiram para a etapa seguinte, que consistiu em analisar, de forma mais minuciosa, quais aspectos o texto abordava, e, assim, uma nova categorização baseada nos eixos escolas públicas e escolas privadas foi realizada. O processo de análise dos dados foi realizado no software ATLAS.ti, e, com base nas categorias de análise, foi realizada a compilação, a descrição e a problematização das histórias (re)produzidas nos textos jornalísticos publicados no jornal no período investigado. Os dados apresentados em três eixos sintetizam o conteúdo encontrado nos textos analisados, tendo como referências o aumento de matrículas de alunos em escolas comuns, a inclusão escolar em escolas públicas e em escolas privadas.

\section{A EDUCAÇÃo INCLUSIVA GANHA ESPAÇO NAS PÁGINAS DO JORNAL: FOCO NA EXPANSÃO DE MATRÍCULAS NAS EXPERIÊNCIAS DAS ESCOLAS COMUNS}

Entre os anos de 1998 e 2004, a expansão da chamada Educação Inclusiva pelo Brasil foi pauta de matérias publicadas no jornal OESP. Em um primeiro momento, o termo pôde ser traduzido como acesso ao ensino regular, baseado no aumento no número de matrículas dos alunos do público-alvo da Educação Especial em classes comuns. Assim, o conceito de Educação Inclusiva, conforme definido na Declaração de Salamanca (Organização das Nações Unidas para a Educação, a Ciência e a Cultura [UNESCO], 1994), em referência ao princípio orientador para o sistema educacional acomodar adequadamente a todos os grupos historicamente marginalizados, é reduzido pelo jornal ao acesso de alunos do público-alvo da Educação Especial à escola comum. Mendes (2017, p. 64), entretanto, argumenta que esse termo "não 
pode ser reduzido ao significado de educação escolar da população-alvo da Educação Especial [...], pois a população a que se refere é muito mais ampla”. Nesse sentido, o emprego do termo "educação inclusiva” nas matérias analisadas apresentaram uma redução do conceito, uma vez que restringiam o público-alvo da Educação Especial, sobretudo os alunos com deficiência.

No âmbito legal e político, o acesso de alunos público-alvo da Educação Especial à classe comum de escolas do ensino regular, traduzido no aumento do número de matrículas, consiste em um indicador importante, embora isso não signifique que o direito à educação esteja sendo garantido. No jornal, entretanto, a expansão do número de matrículas dos alunos público-alvo da Educação Especial ganhou espaço, e foi traduzida como "inclusão", sendo a visibilidade desse tema percebida logo no título das matérias, conforme mostra a Figura 1.

\section{Cresce inclusão de alunos especiais nas escolas}

Cresce inclusão
de deficientes em
escolas comuns

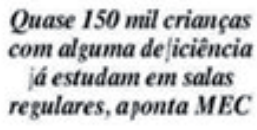

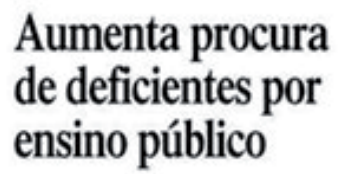

InCLUSÃo

JÁÉ REALIDADE

NA PERIFERIA

Figura 1. Títulos sobre a expansão de matrículas no ensino regular Fonte: Acervo digital O Estado de São Paulo (2002, 2003).

Baseando-se em dados publicados pelo Censo Escolar, de 2001 a 2004, nesse período, cinco matérias noticiaram o aumento significativo no número de matrículas de estudantes público-alvo da Educação Especial no sistema regular de ensino. No dia 24 de maio de 2002, a matéria intitulada Aumenta procura de deficientes por ensino público noticiou o aumento no número de matrículas de alunos público-alvo da Educação Especial, em tom de comemoração. Segundo a matéria, entre os anos de 1998 e 2001, houve um aumento correspondente a 54\% no número de matrículas em escolas comuns, totalizando 78.274 matrículas, destacando, entretanto, a concentração de alunos em turmas do Ensino Fundamental e a prevalência das condiçóes de deficiência intelectual e auditiva.

Entretanto, há de considerar-se que a concentração de matrículas no Ensino Fundamental não era característica apenas do alunado da Educação Especial, uma vez que a faixa de escolarização obrigatória na época era dos 7 aos 14 anos de idade, etapa correspondente ao Ensino Fundamental. Além disso, destacam-se outros fatores que possivelmente contribuíram para isso, tais como a escassez de escolas de Educação Infantil, o gargalo existente na passagem entre o Ensino Fundamental e o Ensino Médio, e os problemas de evasão escolar. Contudo, a matéria também deixou claro que o maior número de matrículas, ou seja, mais de 245 mil, ainda se concentrava fora do ensino regular, em instituiçóes especializadas.

Ainda no ano de 2002, a expansão nas matrículas nacionais voltou a ser noticiada, mas, dessa vez, com base nos dados do Censo Escolar de 2002, notificando um aumento de $36 \%$. Tomando como base o número de matrículas do ano anterior (78.274), o número noticiado passou a representar mais de 106.400 matrículas. A matéria publicada em 2 de setembro de 2003, Cresce inclusão de alunos especiais nas escolas, nas duas edições do jornal, com chamada 
em primeira página, dedicou-se à discussão da expansão das matrículas dos alunos público-alvo da Educação Especial no ensino comum. Os dados do Censo Escolar de 2003 apresentados indicaram o aumento de 30,6\%, chegando-se a 144.583 matrículas na Educação Básica. No final do ano de 2004, os dados do censo foram retomados, noticiando novamente o aumento das matrículas. Segundo a matéria, em 1998, quando o Censo Escolar começou a pesquisar sobre os alunos da Educação Especial, somente 13\% das matrículas do público-alvo da Educação Especial estavam no ensino comum, e, no ano de 2004, o número de matrículas subiu 34,4\%.

Contudo, cabe destacar a inconsistência dos dados, em termos numéricos, apresentados nas matérias. O estudo de Meletti e Bueno (2011), sobre os indicadores sociais do Censo Escolar no âmbito da Educação Especial, apontou que, em 2001, o número de 78.274 matrículas foi em classe especial, e não em classes comuns como induzido pela matéria. Segundo os autores, o número de matrículas no ensino comum foi: 81.344 no ano de 2001, 110.704 em 2002, 145.141 em 2003 e 195.370 em 2004.

Além das inconsistências apresentadas, é preciso considerar que as próprias sinopses estatísticas do Censo Escolar apresentavam imprecisóes no método de coleta de dados em relação à Educação Especial, conforme discutido por Meletti e Bueno (2011), devido a diversos fatores, tais como: a) as categorias referentes aos grupos que compunham o público-alvo da Educação Especial variaram na pesquisa do Censo Escolar de um ano para outro, ocasionando imprecisóes nos dados de matrículas; b) apesar da legislação educacional brasileira deixar claro quais grupos compunham o público-alvo, a classificação ainda era muito arbitrária, principalmente em se tratando da condição de deficiência intelectual. Assim, a prevalência de alunos cadastrados com deficiência intelectual no Censo Escolar, e também nos textos do jornal, precisa ser analisada com cautela, pois não se pode desconsiderar o vínculo estabelecido historicamente entre fracasso escolar e a deficiência intelectual, na qual a condição do aluno foi, e ainda é, utilizada como justificativa do não aprender, além da precariedade que envolve o processo de avaliação e diagnóstico de deficiência intelectual (Veltrone, 2011).

Apesar das limitaçóes apresentadas, ano a ano, o aumento de matrículas de alunos público-alvo da Educação Especial foi pauta no jornal, e, considerando-se o aumento do acesso à escola, o primeiro passo para que a inclusão escolar seja efetivada, embora seja necessário garantir o acesso, é preciso também garantir a permanência e o sucesso escolar desse alunado nas escolas de ensino regular (Mendes, 2006).

Em decorrência de diretrizes internacionais (UNESCO, 1990, 1994) adotadas e impulsionados pela Legislação Federal (Lei No 9.394/1996; Ministério da Educação [MEC], 2001), mudanças em contextos locais foram entâo sendo percebidas. O acesso do público-alvo da Educação Especial à escola comum passou a receber atenção social e se tornou um tema popular. Entre os anos de 1998 e 2004, histórias sobre algumas experiências de inclusão escolar foram narradas pelo jornal, apontando essa forma de escolarização como uma tendência crescente em escolas públicas e privadas. A seguir será descrito o foco dessas matérias quando o assunto eram escolas privadas ou públicas. 


\subsection{A EDUCAÇÃo INCLUSIVA NAS ESCOLAS PRIVADAS: NARRATIVAS DE SUPERAÇÃo E SUCESSO}

As escolas particulares da regiáo metropolitana de São Paulo divulgaram suas experiências de inclusão escolar, geralmente bem-sucedidas, em matérias do jornal OESP. No ano de 1998, no município de São Paulo (SP), por exemplo, uma escola particular de ensino comum e sua companhia de dança realizavam o trabalho educacional e artístico aderindo ao discurso da inclusão. Entretanto, segundo a notícia, para os alunos com deficiência, era oferecida uma rotina diferenciada, logo estes não participavam de todas as atividades com os demais da turma comum, e, assim, parte do horário de atividade escolar era dedicado a atividades direcionadas somente aos alunos com deficiência e outra parte na classe comum.

A matéria Colégios pioneiros têm exemplos bem-sucedidos, publicada em 16 de setembro de 2001, nas duas ediçóes do jornal, apresentou o exemplo de três escolas particulares com a proposta de inclusão escolar de alunos com deficiência. A princípio o texto ressaltou o pioneirismo da iniciativa das escolas que "há anos, e com sucesso utilizam a inclusão", e o trabalho diferenciado realizado com turmas reduzidas para que a professora pudesse dar a atenção necessária a todos. A primeira escola, mencionada na matéria, ofertava Educação Infantil, localizada em um bairro nobre da capital paulista, atendia crianças com idade entre 1 e 7 anos, e, segundo o relato da diretora, $10 \%$ dos alunos possuíam deficiência ou autismo ${ }^{4}$, e, apesar da alta demanda, havia apenas um aluno em condição de deficiência ou autismo em cada sala de aula. Para os alunos com autismo, de acordo com os pais, uma atendente terapêutica era contratada para acompanhar os alunos na sala de aula comum, junto à professora, reforçando a necessidade da sintonia da atendente terapêutica com a professora e com os pais.

A segunda escola privada, também situada em um bairro nobre e de Educação Infantil, há oito anos adotara a inclusão. A matéria retratou a satisfação do pai de duas alunas da escola pelo trabalho realizado e pela estrutura oferecida no processo de aprendizagem das filhas, em especial da filha com Síndrome de Down. O pai relatou o progresso da filha e o desenvolvimento atingido desde que ela ingressara nessa escola.

Por fim, a terceira escola privada, localizada na região central de Guarulhos (SP), que pratica a inclusão desde 1998, informou que 50\% dos alunos possuíam deficiência, e que investia na capacitação dos professores de forma contínua para garantir a qualidade da educação ofertada. Cabe destacar que essa escola publicou em outras ocasióes, e, por diversas vezes, propagandas nesse jornal, a partir do ano 2000.

Interessante observar que, no anúncio, a Educação Inclusiva aparecia juntamente às etapas de ensino e atividades extracurriculares ofertadas pela escola, dando a entender que a Educação Inclusiva era mais um serviço ofertado e não uma filosofia assumida pela escola. Outra hipótese refere-se ao emprego do termo Educação Inclusiva usado para substituir o termo Educação Especial, indicando a oferta dessa modalidade de ensino. Os textos divulgaram o nome das escolas e o slogan da inclusão escolar e da Educação Inclusiva, porém não ofereceram elementos para que se pudesse compreender ou inferir a forma como o trabalho pedagógico e a organização escolar eram conduzidos.

${ }^{4}$ Cabe destacar que, na matéria em questão, a condição de autismo foi referida como uma condição de deficiência. 
Uma vitória na luta pela igualdade: Aluno com problemas de visão muda rotina, mas amplia as possibilidades de aprendizado de uma turma tradicional foi o título de uma matéria publicada no dia 19 de novembro de 2004, em destaque no jornal, com uma página e meia, incluindo fotos. O texto foi dedicado a relatar a experiência de escolarização de um garoto de três anos de idade, com baixa visão, em uma escola particular de Educação Infantil, abordando os fatores que levaram a família a escolher uma escola comum, bem como suas expectativas. A máe do aluno, uma administradora de empresas, contou que não havia sido fácil a decisão de matricular o filho em uma escola comum, mas que, no entanto, o desenvolvimento social e a convivência junto às crianças sem deficiência foi, em sua opiniâo, decisivo. Passado o período de adaptação, família e escola avaliaram de forma positiva o desenvolvimento social do garoto. Em relação ao ensino, a turma era composta por 15 alunos e contava com uma auxiliar cuja incumbência era de acompanhar mais de perto o aluno com baixa visão. Entretanto, foi ressaltado o engajamento de toda a equipe escolar, inclusive em capacitação docente para o trabalho pedagógico adequado às condiçóes do aluno, conforme evidenciado na Figura 2.

\section{As atividades na sala de aula crianças também”, avalia Mar- tiveram de ser adaptadas: bar- cela. Na hora de contar histó- bantes contornando formas geo- rias para a turma, as professo- métricas; números, letras e figu- ras entregam ao Matheus obje- ras em escala maior e materiais tos de formas diversas para ele com texturas diferenciadas. "Fi- associá-los aos personagens. cou mais rico, para as outras}

Figura 2. Excerto: Adaptação de atividades Fonte: Acervo digital de O Estado de São Paulo (2004).

As adequações nas atividades descritas, segundo a matéria do jornal, permitiram que o aluno com deficiência visual participasse das atividades e tivesse acesso ao conteúdo curricular, de acordo com a idade e a fase de escolarização. O trecho "Ficou mais rico, para as outras crianças também" é bastante interessante e diferenciado, principalmente nesse período, em que as adequaçóes eram pensadas e utilizadas apenas para o aluno-alvo, mas que acabaram beneficiando toda a turma.

Outro ponto de destaque nas experiências narradas pelo jornal refere-se à opinião dos pais de alunos sobre a inclusão escolar, mais precisamente sobre seus filhos estudarem junto aos alunos com deficiência, assunto que também ganhou certo espaço nas matérias. Em 1998, uma professora de ensino regular, que atuava junto aos alunos com e sem deficiência, relatou que alguns pais de alunos foram contrários à iniciativa e retiraram os filhos da escola. Ela afirmou que os pais que mantiveram os alunos o fizeram porque acreditavam na proposta e em seus benefícios.

Nos anos de 2001 a 2004, sempre houve trechos nas matérias em que uma diretora ou professora destacava o fato de que os pais dos alunos sem deficiência estavam sempre de acordo com a iniciativa adotada. Cabe questionar o que aconteceria caso algum pai de aluno se opusesse à prática de inclusão escolar, e se a escola abriria mão da inciativa e dos princípios em questão. 
O convívio entre alunos com e sem deficiência também obteve destaque, reiteradamente em matérias que destacaram a importância dessa interação desde a mais tenra idade, e o aprendizado sobre o respeito às diferenças e à diversidade, conforme se pode observar nos trechos selecionados a seguir na Figura 3.

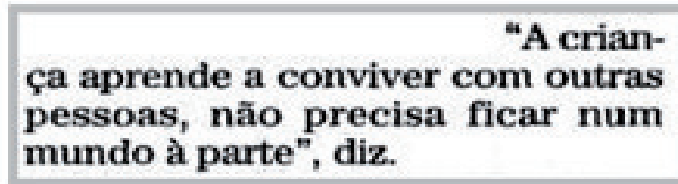

26-02-1998; ed. SP/Na

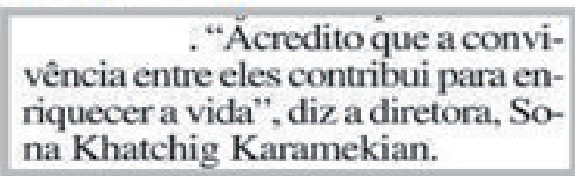

19-11-2004; ed. SP/Na
"As outras crianças também têm um ganho ao conviver com alguém diferente. Elas vão se tornar adultos e vão conviver com as diferenças numa boa", ressalta. "O preconceito está no adulto e não na criança."

19-11-2004; ed. SP/Na

Figura 3. Benefícios da convivência

Fonte: Acervo digital de O Estado de São Paulo $(1998,2004)$.

Assim, a convivência entre os alunos foi considerada um benefício, para que as crianças aprendessem a conviver e respeitar a diversidade e a especificidade de cada um, além de desmistificar a condição de deficiência, fazendo com que todos compreendessem que as diferenças existiam, mas que deviam ser vistas de forma natural. No entanto, faz-se necessário refletir se somente a convivência e a socialização seriam capazes de acabar com preconceitos e estereótipos e se seria apenas esta a função da escola para com essa população, ou seja, a de promover a socialização e a mudança nas atitudes dos alunos sem deficiência.

$\mathrm{Na}$ perspectiva de garantia do direito à educação, caberia destacar que somente o acesso à escola comum e a convivência dos alunos não é suficiente. Para minimizar preconceitos e estereótipos, é preciso um trabalho pedagógico consciente e organizado de forma a permitir que os alunos realmente aprendam a respeitar as diferenças. Entretanto, isso tudo não exime a escola de dar acesso ao currículo a todos os alunos, à medida que a presença dos alunos público-alvo da Educação Especial nas escolas comuns deve ir muito além da convivência e da socialização. Nos textos, a questão da socialização ganhou maior ênfase do que a questão do acesso ao currículo, induzindo ao entendimento de que esta é a razão de se desenvolver ambientes escolares inclusivos.

\subsection{A EducaÇáo InClusiva nas escolas públicas: narrativas de problemas e de DESAFIOS}

Em oposição às experiências bem-sucedidas das escolas particulares, o jornal OESP apresentou também algumas histórias sobre a inclusão escolar de alunos com deficiência nas redes públicas de ensino paulistas, estadual e municipal, sendo raros, nesses casos, os exemplos bem-sucedidos, mais precisamente apenas um caso, entre os demais nos quais se concluía que experiência não estava sendo bem avaliada. 
Ao abordar e divulgar os dados de uma tese de Doutorado sobre a inclusão de alunos surdos na Rede Estadual de Ensino de São Paulo, a matéria apresentou a história de uma jovem surda de 14 anos de idade, matriculada aos 7 anos de idade em uma escola comum, cuja experiência foi malsucedida. No mesmo ano, sua mãe a retirou da escola e a colocou em uma escola especial, onde permaneceu até a quarta série, quando então retornou à escola comum. A aluna passou a ser considerada um exemplo de superação ao atingir nota superior à de alguns colegas, sem deficiência, na prova do Sistema de Avaliação do Rendimento Escolar do Estado de São Paulo (Saresp). Entretanto, este foi apresentado como um caso isolado, uma exceção à regra de uma aluna que combinou escolarização em escolas especial e comum.

A pedagoga da escola em que a jovem estudava, ao afirmar que "o mundo do deficiente auditivo é muito limitado porque ele não ouve”, conforme evidenciado na Figura 4, colocou a condição de deficiência como limitadora da aprendizagem e do desenvolvimento intelectual. Nessa perspectiva, nada inclusiva, o foco recaiu sobre a condição dos alunos, deixando de considerar as condiçóes de ensino para que eles se desenvolvessem e aprendessem. Outro aspecto que se pôde inferir, com base na fala da pedagoga, se atrelou ao fato de que nenhum trabalho pedagógico especializado foi realizado junto à aluna, a fim de responder adequadamente às suas especificidades. Assim como no caso apresentado, alunos com deficiência seguiram em escolas regulares sem nenhum tipo de apoio previsto pela legislação, sendo os casos de sucesso e de superação considerados exceção à regra, e o insucesso escolar desses alunos justificado pela condição de deficiência.

\section{"O mundo do deficien- ciplinas que trabalham com te auditivo é muito limitado dados concretos. Tudo o que porque ele não ouve. Por isso, envolve texto é mais compli- ele costuma ir melhor nas dis- cado para ele", diz Denise.}

Figura 4. Concepção da pessoa com Surdez/Deficiência Auditiva Fonte: Acervo digital O Estado de São Paulo (2002).

No geral, percebe-se que a concepção clínica sobre a condição de deficiência ainda permeava os textos jornalísticos, com alguns textos colocando a condição de deficiência como fator limitador ao processo de aprendizagem, sem contextualizar o quanto as condiçóes deficitárias de ensino compunham esses resultados. Assim, as dificuldades que muitos alunos com surdez/deficiência auditiva apresentavam com textos, decorrentes da falta de um processo limitado de desenvolvimento da linguagem e aquisição de uma língua, comprometiam o desempenho desses alunos e os colocavam em situação de defasagem escolar, demandando "elaboração de propostas educacionais que atendam às necessidades dos sujeitos surdos, favorecendo o desenvolvimento efetivo de suas capacidades" (Lacerda, 2006, p. 165).

Para que a inclusão escolar se efetive e obtenha sucesso, é imperativo que a escola brasileira mude, se transforme, e seja de qualidade para todos. Entretanto, a escola comum apresenta diversos problemas e dificuldades, e a qualidade da educação ofertada está há muito tempo comprometida para todos os alunos, principalmente para aqueles que apresentam im- 
pedimentos. Assim, tendo em vista os índices das avaliações em larga escala, os indicadores do censo escolar (Instituto Nacional de Estudos e Pesquisas Educacionais Anísio Teixeira [INEP], 2017) e pesquisas sobre as condiçóes educacionais, de forma geral, pode-se constatar que as más condiçôes de ensino e a necessidade de reestruturação do sistema educacional não se faz necessária apenas para os alunos público-alvo da Educação Especial.

A crise educacional é geral, e, por isso, a escola precisa mudar por e para todos. Entretanto, as dificuldades foram evidenciadas nas matérias de jornal quando envolveram essa população específica e as escolas públicas, embora a responsabilidade pelas dificuldades no discurso jornalístico ainda tenham sido atribuídas à condição dos alunos e não à crise educacional do país.

A reestruturação necessária do ensino e das escolas também foi abordada nas matérias. Ao longo dos textos que abordaram o tema de inclusão escolar, diversas ressalvas foram realizadas, sobretudo em relação à inclusão escolar nas escolas da rede pública de ensino, estadual e municipal. As más condiçóes do ensino público foram apontadas e colocadas como fatores que impediam o sucesso da proposta.

A Figura 5 ilustra, em três excertos das matérias, as narrativas recorrentes nos textos, em que, ao mesmo tempo que se reconhece a importância da inclusão escolar, se fazem ressalvas.

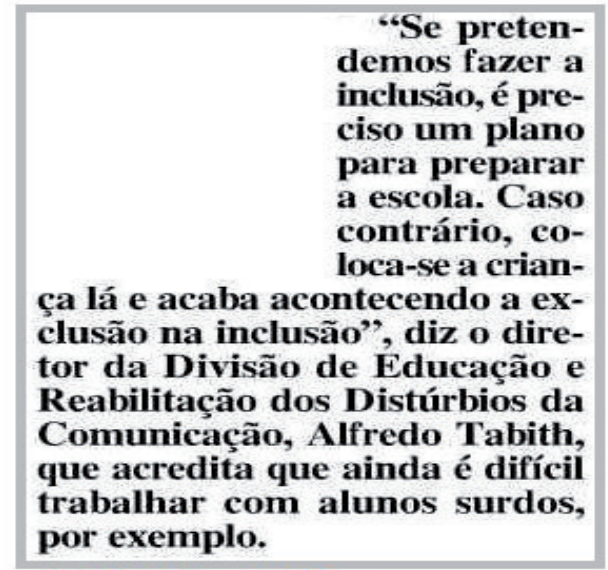

02-09-2003; ed. SP/Na

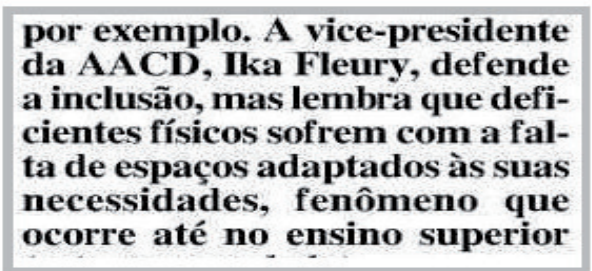

02-09-2003; ed. SP/Na

"A inclusão é muito importante para as crianças e também para as escolas, mas é preciso que as escolas tenham condições para aceitar esses alunos especiais".

18-02-2004; ed. SP/Na

Figura 5. Ressalvas sobre inclusão escolar Fonte: Acervo digital O Estado de São Paulo (2003, 2004).

O primeiro trecho apresenta a fala do diretor da Divisão de Educação e Reabilitação dos Distúrbios da Comunicação, cuja ressalva refere-se à falta de planejamento e de diretrizes para o processo de inclusão escolar. Assim, as orientaçóes traçadas por meio dos documentos oficiais do Governo foram consideradas extremamente importantes; entretanto, ainda continham caráter genérico com orientações gerais e muito abrangentes. A capacitação docente e as adaptaçóes no ambiente escolar foram consideradas previstas, mas ainda careciam de operacionalização, com planos de açóes que considerassem os diferentes contextos e as reais necessidades de cada unidade escolar. 
A formação docente para o desenvolvimento de um trabalho pedagógico inclusivo foi abordada por diversas vezes. Antes de tudo, destacou-se a crítica à condição de formação docente para atuar junto aos alunos público-alvo da Educação Especial. Em relatos de profissionais especialistas, familiares e dos próprios docentes, foi reconhecido o despreparo do corpo docente, em decorrência de uma formação que pouco, ou nada, contemplava a especificidade do ensino dessa população, ainda que em linhas gerais.

Para o desenvolvimento de uma educação verdadeiramente inclusiva, a formação docente seria essencial, e a matéria intitulada Professores provocam cenas de preconceito, publicada em 16 de setembro de 2001 na edição SP, abordou tal questão, com base nos resultados obtidos em uma tese de Doutorado. O texto, apresentado na Figura 6, iniciou com o seguinte conteúdo:

\section{Docentes mal preparados não sabem como lidar com aluno deficiente

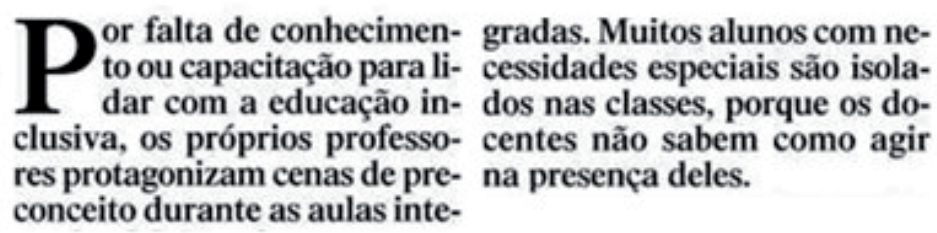

Figura 6. O impacto da falta de formação docente frente à inclusão escolar Fonte: Acervo digital O Estado de Sáo Paulo (2001).

Além do título, o início do texto também foi bastante impactante, ao apontar cenas de preconceitos vivenciadas por alunos com deficiência, em turmas do ensino comum, principalmente da parte dos professores. No entanto, o texto esclarecia que a ação dos professores participantes da pesquisa foi decorrente do despreparo que, sem qualquer tipo de capacitação ou apoio especializado, recebiam em suas turmas algum aluno com deficiência. $\mathrm{O}$ texto informou que os alunos com deficiência eram isolados em determinados espaços da sala de aula pela professora como uma medida preventiva, como, por exemplo, no caso de um aluno com deficiência visual que ficava a frente de todos, próximo à professora para não ser agredido pelos colegas, além de outro caso de aluno com deficiência intelectual, que ficava em um canto ao fundo da sala de aula para não agredir seus colegas. Sobre esse aspecto residem dois problemas: 1) justificar os problemas de comportamento e indisciplina com base na condição dos alunos e em estereótipos; e 2) visão preconceituosa da pessoa com deficiência como indefesa ou como incontrolável.

A segunda cena de preconceito narrada esteva relacionada ao aluno com deficiência visual, alfabetizado por meio do sistema Braille. Em uma aula, foi observado que a professora se negou a corrigir o trabalho do aluno escrito por meio do sistema Braille, porque ela não entendia os pontinhos (fala da professora na matéria) e não reconhecia o sistema Braille com uma forma legítima de escrita.

A capacitação docente foi então apontada como necessária e urgente para que cenas como essas não se repetissem. Além das dificuldades no ensino do conteúdo escolar para os alunos com deficiência, em função das especificidades de cada grupo e sujeito do público-alvo da Educação Especial, foi destacado que, sem a devida orientação, os estereótipos e os precon- 
ceitos dos professores poderiam ser reforçados, comprometendo duas premissas da inclusão escolar: a permanência e o sucesso escolar.

Em um contexto que destacava com frequência a demanda por formação, a capacitação docente, a realização de diversos cursos de formação foi divulgada pelo jornal OESP, entre os anos de 1998 e 2004, tanto por instituiçóes particulares quanto pelos Governos, Federal e do estado de São Paulo. Além disso, notou-se que as instituições particulares de Ensino Superior, Universidades e Faculdades, veicularam diversas propagandas de cursos de especialização, e que, entre os cursos ofertados, havia os de especialização na área da Educação Especial, com foco na Educação Inclusiva, apesar de diferentes nomes serem utilizados por cada instituição de ensino para determinar esse tipo de formação.

Assim, com diversas críticas ao ensino público e à formação docente deficitária, os Governos Federal e Estadual de São Paulo também anunciaram suas iniciativas para lidar com o problema, visando a melhoria nas condiçóes de ensino. Na matéria intitulada Estado promete melhorar programa, a Secretaria de Estado da Educação admitiu as falhas no ensino e prometeu mudar o quadro até o ano de 2002, por meio da capacitação de 104 mil professores da rede e da parceria com o Governo Federal, o qual distribuiria livros didáticos em Braille e promoveria cursos de capacitação a distância.

Cabe destacar que, no mesmo dia, no caderno principal do jornal, três matérias foram publicadas sobre a inclusão escolar na rede pública do estado de São Paulo, duas delas tecendo críticas e denunciando as carências da rede pública, e a outra apresentando algumas medidas do Governo Estadual e Federal para minimizar os problemas. A Figura 7 apresenta o layout da página em que os textos foram publicados. $\mathrm{O}$ destaque foi dado para as matérias que abordaram as dificuldades da escola pública e denunciaram as más condiçóes do ensino que prejudicavam o processo de inclusão escolar. Contudo, a matéria com o pronunciamento do Governo Estadual e a promessa de mudança apareceu como uma medida redentora para envolver o leitor, a favor do Governo Estadual, pois ao mesmo tempo que se fazia uma denúncia à política, se oferecia ao Governo Estadual a oportunidade de se retratar e de justificar os fatos, no final da página. 


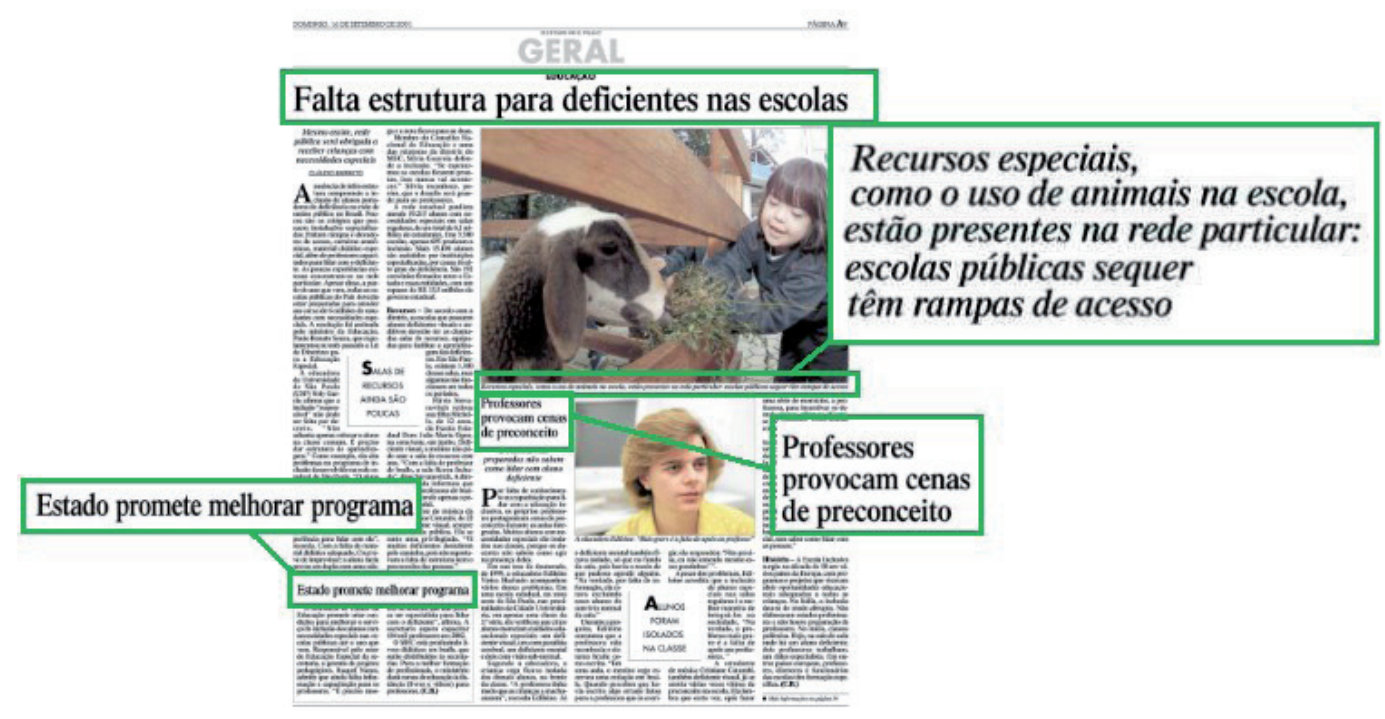

Figura 7. Análise de layout da página

Fonte: Acervo digital de O Estado de São Paulo (2001).

Outro aspecto que ganhou visibilidade foi a ressalva sobre a quantidade de alunos nas classes comuns. Nas matérias sobre escolas particulares, foi destacado que o número de alunos nas salas foi reduzido quando alunos com deficiência foram inseridos, realidade não adotada na rede pública, criticada pelo alto número de alunos na sala. Tal fator, como alegado, dificultaria o trabalho do professor em dispensar a atenção necessária aos alunos, sobretudo aos alunos público-alvo da Educação Especial, que supostamente demandariam mais apoio no processo de aprendizagem.

Conhecer e reconhecer as dificuldades do sistema educacional faz-se fundamental para que medidas sejam adotadas a fim de superá-las, assim como é primordial que os meios de comunicação em massa, como o jornal, esteja atento e denuncie essa realidade, que seja crítico às condiçốes educacionais e à organização do sistema. Entretanto, é preciso cautela para que essas questóes não sejam utilizadas como justificativas para não se garantir o direto dos alunos público-alvo da Educação Especial, e, principalmente, para que a condição desse alunado não seja utilizada como explicação às dificuldades que as escolas apresentam.

\section{Consideraçótes Finais}

Ao final da década de 1990, o debate sobre a inclusão escolar começou a ganhar espaço, ainda que restrito, no jornal OESP. O aumento no número de matrículas dos alunos público-alvo da Educação Especial foi notícia ano a ano, trazendo os dados do censo escolar, que, embora inconsistentes, foram utilizados como prova de resultados da implementação de políticas educacionais inclusivas, que visavam a garantia de acesso do público-alvo da Educação Especial à escolarização formal. 
Ainda que os princípios da Educação Inclusiva abarquem uma gama diversificada de grupos minoritários, que, no decorrer da história, estiveram fora ou à margem do sistema educacional, o público-alvo da Educação Especial obteve destaque e centralidade nas discussões acerca desse tema. Em decorrência do aumento no número de matrículas, algumas experiências de inclusão escolar foram sendo narradas pelo jornal OESP.

Segundo o jornal, a prática de inclusão escolar chegou primeiro nas escolas particulares com matérias anunciando experiências apresentadas como bem-sucedidas, destacando os pontos positivos e a infraestrutura dessas escolas para receber alunos com deficiência, com a ressalva de que o atendimento fosse destinado a alunos com deficiências consideradas de grau leve. Poucos indícios sobre a prática realizada nas escolas foram testemunhados nos textos publicados pelo jornal. As dificuldades dessas escolas em nenhum momento foram abordadas, e o resultado pareceu implicar em boas propagandas de escolas particulares, nas quais as matérias sobre inclusão contribuíram para divulgar suas marcas. Apesar desse aspecto, considera-se que a divulgação pela mídia de boas experiências foi importante para que a população tomasse conhecimento dessa possibilidade, uma vez que, para muitos até então, o lugar do público-alvo eram apenas escolas ou instituiçóes especializadas.

Nas matérias sobre a inclusão escolar em escolas da rede pública de ensino, mudou-se a tônica, prevalecendo as críticas ao despreparo das escolas para receber os alunos público-alvo da Educação Especial. Quando o assunto era a inclusão nas escolas públicas, questóes relacionadas à falta de formação docente, recursos e infraestrutura ganharam destaque. No entanto, não se pode esquecer que a precariedade que impera em muitas escolas públicas se restrinja ao processo de escolarização dos alunos público-alvo, uma vez que a melhoria na qualidade de ensino seria importante para todos os alunos.

De modo geral, as matérias de jornal reforçam o mito de que as escolas privadas são de boa qualidade e estão preparadas para acolher o aluno com deficiência, enquanto que a escolas públicas enfrentam apenas desafios e dificuldades. Duarte (2013), em estudo sobre o impacto da pobreza no Índice de Desenvolvimento da Educação Básica (Ideb), evidenciou o imenso quantitativo de pobres nas escolas públicas do Brasil, chamando atenção para a invisibilidade da pobreza que possibilita à escola adotar práticas que rotulam e estigmatizam alunos pobres como indisciplinados, lentos, defasados, atrasados, e, assim, a pobreza é transformada em atributos e impressóes que coisificam os alunos e as famílias desse estrato.

Em síntese, quando se trata de matérias sobre a política de inclusão escolar, o que o jornal veicula é que há, por um lado, uma escola pública para alunos pobres que é de má qualidade, e uma escola privada para os que podem pagar, que é acolhedora e efetiva para alunos com deficiências. Entretanto, a desigualdade da qualidade educacional entre escolas, se é que ela existe, fere o caráter democrático e universal da educação determinada na Constituição Federal.

O presente artigo enfocou-se na comparação entre os textos que abordaram as políticas e as práticas de inclusão escolar em instituiçôes públicas e privadas. Todavia, cabe destacar que essas foram apenas algumas das histórias veiculadas pelo jornal, ao lado de tantas outras, que nos oferecem a noção de que ainda se faz necessário educar toda a sociedade, com a finalidade de acelerar e facilitar o processo de aceitação da diferença nos diferentes contextos sociais, principalmente nas escolas. Dessa forma, os meios de comunicação de massa - jornal, 
rádio, televisão, internet e vídeo educativo -, surgem como as principais alternativas para essa mudança de larga escala.

No caso específico do jornal impresso, como veículo de comunicação de massa, ao mesmo tempo que reproduz as representaçóes coletivas sobre deficiência da sociedade em geral, também pode ter um papel fundamental como divulgador de mensagens, as quais deveriam contribuir para a transformação do imaginário social e do estigma. No caso, percebe-se que ainda predominam mensagens contraditórias que enfatizam a melhor qualidade das escolas privadas, que valorizam as instituições especializadas filantrópicas e, ao mesmo tempo, colocam os impedimentos decorrentes das deficiências no cerne das impossibilidades das escolas públicas se constituírem como espaços cada vez mais inclusivos.

\section{REFERÊNCIAS}

Cellard, A. (2008). A análise documental. In J. Poupart, J. P. Deslauriers, L. H. Groulx, A. Laperièrre, R. Mayer, \& A. P. Pires (Orgs.), A pesquisa qualitativa: Enfoques epistemológicos e metodológicos (pp. 295-316). Petrópolis: Vozes.

Duarte, N. S. O impacto da pobreza no Ideb: Um estudo multinível. Revista Brasileira de Estudos Pedagógicos, 94(237), 343-363.

Estado de São Paulo (1998). Estado de São Paulo (2001). Falta de estrutura para deficientes nas escolas. Acervo Digital Jornal o Estado de São Paulo: Caderno Geral, A12.

Estado de São Paulo (2001). Falta de estrutura para deficientes nas escolas. Acervo Digital Jornal o Estado de São Paulo: Caderno Geral, A9.

Estado de São Paulo (2002). Aumenta procura de deficientes por ensino público. Acervo Digital Jornal o Estado de São Paulo: Caderno Geral, A12.

Estado de São Paulo (2003). Cresce inclusão de alunos especiais nas escolas. Acervo Digital Jornal o Estado de Sáo Paulo: Caderno Geral, A1.

Estado de São Paulo (2004). Um colégio para todos, com aulas de igualdade. Acervo Digital Jornal o Estado de São Paulo: Caderno Seu Bairro, ZL16.

Gouveia, D. F. (2013). A história da educação especial no município de São Carlos com base na mídia impressa: 2001 a 2004 (Trabalho de Conclusão de Curso). Departamento de Psicologia, Centro de Educação e Ciências Humanas, Universidade Federal de São Carlos, São Carlos, SP, Brasil.

Grillo-Stábille, C. C. (2013). A história da educação especial no município de São Carlos com base na mídia impressa: 2005-2008 (Trabalho de Conclusão de Curso). Departamento de Psicologia, Centro de Educação e Ciências Humanas, Universidade Federal de São Carlos, São Carlos, SP, Brasil.

Instituto Nacional de Estudos e Pesquisas Educacionais Anísio Teixeira (2017). Sistema Nacional da Educação Básica, Avaliaçâo Nacional de Alfabetização (ed. 2016, 25 p.). Brasília, DF: INEP.

Lacerda, C. B. F. (2006). A inclusão escolar de alunos surdos: O que dizem alunos, professores e intérpretes sobre esta experiência. Caderno Cedes, 26(69), 163-184.

Le Goff, J. (2003). História e Memória (5a ed., pp. 419-476). Campinas, SP: UNICAMP. 
Lei no 9.394, de 20 de Dezembro de 1996. Estabelece as diretrizes e bases da educação nacional. Recuperado em 5 de julho de 2018 de http://www2.camara.leg.br/legin/fed/lei/1996/lei-9394-20dezembro-1996-362578-normaatualizada-pl.html.

Manzini, J. E. (2003). Análise de artigos da revista brasileira de educação especial (1992-2002). Revista Brasileira de Educação, 9(1), 13-24.

Meirelles, W. R. (2002). Ler, ouvir e ver: A revolução documental na pesquisa histórica: Uma abordagem das formas da construção da história. História \& Ensino, 8, 143-150.

Meletti, S., \& Bueno, J. G. S. (2011). O impacto das políticas públicas de escolarizaçáo de alunos com deficiência: Uma análise dos indicadores sociais no Brasil. Linhas críticas, 17(33), 367-383.

Mendes, E. G. (2006). A radicalização do debate sobre inclusão escolar no Brasil. Revista Brasileira de educação especial, 11, 387-405.

Mendes, E. G. (2017). Sobre alunos “incluídos” ou "da inclusão": Reflexôes sobre o conceito de inclusão escolar. In S. L. Victor, A. B. Vieira, I. Martins (Orgs.), Educação especial inclusiva: Conceituaçóes, medicalização e políticas (pp. 60-83). Campos dos Goytacazes, RJ : Brasil Multicultural.

Mendes, E. G., Santos, K. da S., \& D’Affonseca, S. M. (2016) . Histórias da Educação Especial em São Carlos nas folhas de jornal local. In V. L. J. Chaves, \& E. C. de Souza (Orgs.), Documentação, memória e história da Educação no Brasil (1a ed., v. 2, pp. 97-116). São Paulo: Copiart.

Ministério da Educação (2001). Diretrizes Nacionais para a Educação Especial na Educaçáo Básica. Brasília: MEC. Recuperado em 5 de julho de 2018 de http://portal.mec.gov.br/seesp/arquivos/pdf/ diretrizes.pdf.

Nóvoa, A. (1997). A imprensa de educação e ensino: Concepção e organização do repertório português. In D. B. Cattani, \& M. H. C. Bastos (Orgs.), Educação em revista: A Imprensa Periódica e a História da Educação (p. 11-33). São Paulo: Escrituras.

Organização das Nações Unidas para a Educação, a Ciência e a Cultura (1990). Declaração Mundial sobre Educação para Todos: Satisfação das necessidades básicas de aprendizagem. Jomtien-Tailândia: UNESCO.

Organização das Nações Unidas para a Educação, a Ciência e a Cultura (1994). Declaração de Salamanca: Sobre Princípios, Politicas e Práticas na Área das Necessidades Educativas Especiais. SalamancaEspanha: UNESCO.

Pontes, B. S., Noujorks, M. I., \& Sherer, A. (2001). Mídia impressa, discurso e representação social: a constituição do sujeito deficiente (p. 1-6). In Anais do Congresso Brasileiro da Comunicação, Campo Grande, MS, Brasil, 24.

Santos, K. S. (2013). A história da educação especial em São Carlos com base na mídia impressa: 1996-2000 (Trabalho de Conclusão de Curso). Departamento de Psicologia, Centro de Educação e Ciências Humanas, Universidade Federal de São Carlos, São Carlos, SP, Brasil.

Toledo, C. A. A., \& Gimenez, J. C. (2009). Educação e pesquisa: Fontes e documentos. In A. P. B. S. Casimiro, J. C. Lombardi, \& L. D. R. Magalhães (Orgs.), A pesquisa e a preservação de fontes para a educação, cultura e memória (pp. 109-125). Campinas: Alínea.

Veltrone, A. A. (2011). Inclusão escolar do aluno com deficiência intelectual no estado de São Paulo: Identificação e caracterização (Tese de Doutorado). Programa de Pós-Graduação em Educação Especial, Centro de Educação e Ciências Humanas, Universidade Federal de São Carlos, São Carlos, SP, Brasil. 
Vieira, C. E. (2007). Jornal diário como fonte e como tema para a pesquisa em História da Educação: Um estudo da relação entre imprensa, intelectuais e modernidade nos anos de 1920. In M. A. T. Oliveira (Org.), Cinco estudos em História e Historiografia da Educação (pp. 11-40). São Paulo: Autêntica.

Vimieiro, A. C., \& Maia, R. C. M. (2001). Enquadramentos da mídia e o processo de aprendizado social: Transformaçóes na cultura pública sobre o tema da deficiência de 1960 a 2008. E-Compós, 14(1), 1-22.

Zanlorenzi, C. M. P. (2010). História da educação, fontes e a imprensa. Revista HISTEDBR, (40), 60-71.

Recebido em:20/03/2018

Reformulado em: 29/05/2018

Aceito em: 29/05/2018 